\title{
Fractured Perspectives: Movement and Light
}

\author{
Shannon Cuykendall, Steve DiPaola, Reese Muntean, Prophecy Sun \\ School of Interactive Arts + Technology, Simon Fraser University \\ 250-13450 102 Avenue Surrey, British Columbia V3T 0A3, Canada \\ scuykend@sfu.ca, sdipaola@sfu.ca,rmuntean@sfu.ca,pdsun@sfu.ca
}

\section{DESCRIPTION}

In our media-saturated society we experience a new type of fractured reality, made up of multiple converging perspectives and identities that play out in virtual and physical realms. We display our fractured selves through a multitude of platforms and take on different versions of our identities from mothers to activists to shameless self-promoters. Traces of ourselves and others become ghostly whorls of past, future, and present times. In Fractured Perspectives: Movement and Light we explore these fragmented realities through integrating improvisational movement, $360^{\circ}$ camera technology, multiple traditional cameras, tangible props, artificial intelligence based painterly abstraction processing, and processed vocal soundscapes.

As we adapt to this era of multiplicity, our ideas of space and time are shifting. Our perspectives are entangled in an undefined, expanding continuum, where space, time, objects, movement, sound, and style can be combined, separated, configured, and recombined in limitless fashion. Through our artmaking process and research we ask: What are these hybrid entities we create and how do they redefine our conceptions of space, time, objects, movement, sound, and style? To answer these questions, we draw inspiration from contemporary movement scores, performance art, cinematic film, and abstract art. We seek to confront multiplicity in all its forms as we navigate fractured traces of ourselves.
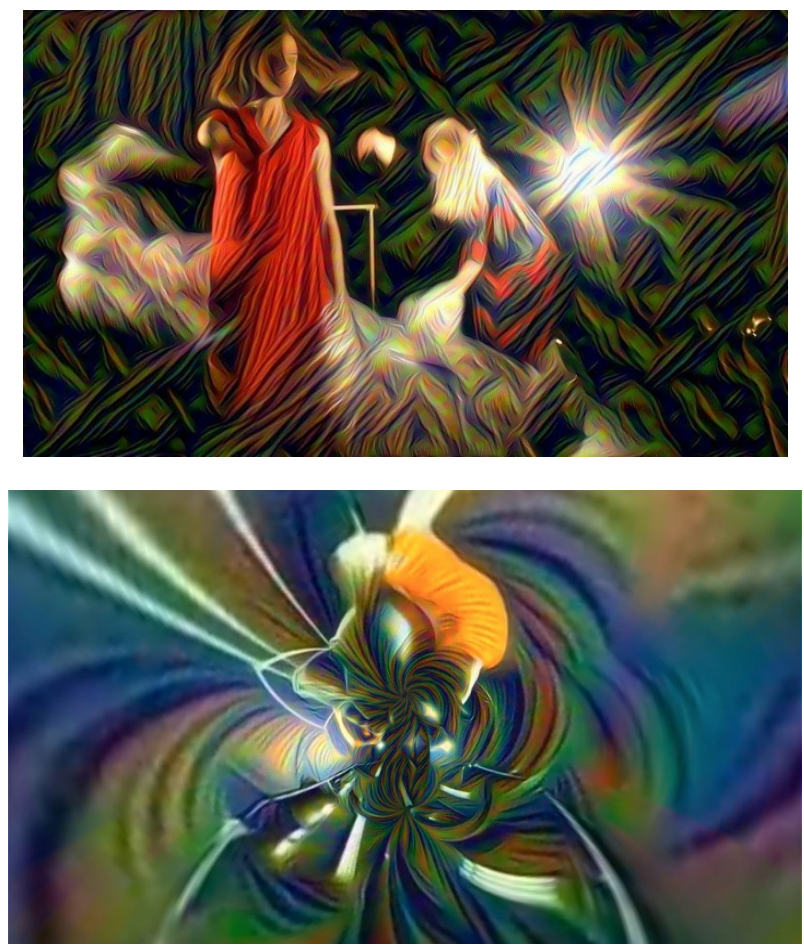

Figure 1 \& 2: Performance video stills, 2017. These stills demonstrate artificial intelligence based abstraction processing using traditional cameras (top) and $360^{\circ}$ camera technology (bottom). 